\title{
High Farnesoid X Receptor (FXR) expression is a strong and independent prognosticator in invasive breast carcinoma
}

\author{
C. GIAGINIS ${ }^{1,2}$, D. KARANDREA ${ }^{1}$, P. ALEXANDROU ${ }^{1}$, I. GIANNOPOULOU ${ }^{1}$, G. TSOUROUFLIS ${ }^{1}$, C. TROUNGOS ${ }^{3}$, E. DANAS ${ }^{1}$, A. KERAMOPOULOS ${ }^{1}$, \\ E. PATSOURIS ${ }^{1}$, L. NAKOPOULOU ${ }^{1}$, S. THEOCHARIS ${ }^{1, *}$
}

${ }^{1}$ First Department of Pathology, National and Kapodistrian University of Athens, Medical School, Athens, Greece; ${ }^{2}$ Department of Food Science and Nutrition, University of the Aegean, Myrina, Lemnos, Greece; ${ }^{3}$ Department of Biochemistry, University of Athens, Medical School, Athens, Greece

*Correspondence: statheocharis@yahoo.com; stamtheo@med.uoa.gr

Received September 1, 2016 / Accepted February 8, 2017

\begin{abstract}
Farnesoid X Receptor (FXR), a nuclear receptor superfamily member, is related with bile acids, glucose and lipids metabolism and recently with cancer. In the present study the clinical significance of FXR expression in invasive breast carcinoma was evaluated. FXR protein expression was assessed immunohistochemically on paraffin-embedded breast cancer tissues obtained from 115 breast cancer patients and was statistically analyzed with clinicopathological parameters, estrogen receptor (ER), progesterone receptor (PR) and human epidermal growth factor receptor 2 (HER2) expression, as well as with tumor cells' proliferative capacity and overall and disease-free patients' survival. FXR positivity was noted in 91 (79.1\%) and high FXR expression in 51 (44.3\%) out of 115 invasive breast carcinoma cases. High FXR expression was significantly associated with smaller tumor size $(\mathrm{p}=0.0318)$ and increased tumor cells' proliferative rate $(\mathrm{p}=0.0375)$. Invasive breast carcinoma patients presenting high FXR expression showed significantly longer overall and disease-free survival times compared to those with low FXR expression (log-rank test, $\mathrm{p}=0.0052$ and $\mathrm{p}=0.0058$ ). In multivariate analysis, FXR expression was identified as independent prognostic factor of overall and disease-free patients' survival (Cox-regression analysis, $\mathrm{p}=0.0023$ and $\mathrm{p}=0.0049$, respectively). The present data support evidence that FXR may be implicated at the earlier stage of breast malignant disease progression, being a strong and independent prognosticator of favorable overall and disease-free survival in invasive breast carcinoma.
\end{abstract}

Key words: FXR, breast cancer, immunohistochemistry, clinicopathological parameters, patients' prognosis

Farnesoid X Receptor (FXR), initially cloned at 1995, belongs to a group of metabolic nuclear receptors, including Vitamin D Receptor (VDR), Pregnane X Receptor (PXR), Liver X Receptor (LXR) and Constitutive Androstane Receptor (CAR) [1,2]. FXR mainly regulates several genes involved in bile acid, lipid and glucose metabolism, by binding to DNA either as a monomer or an heterodimer with common partners for nuclear receptors, Retinoid X Receptors (RXRs) [1, 2]. FXR is highly expressed in the liver, intestine, kidney and adrenals [3]. Two known FXR genes exist, the Fxr $\alpha$ and $F x r \beta$. In humans, Fxr $\alpha$ gene encodes four FXR $\alpha$ isoforms (FXRal, FXR $\alpha 2$, FXR $\alpha 3$ and FXR $\alpha 4$ ) as a result of different promoters and alternative RNA splicing [3], while $F x r \beta$ is a pseudogene with uncertain role [3]. Most FXR target genes are independently regulated by all FXRa isoforms, while other target genes, including those encoding intestinal bile acid binding protein (IBABP), syndecan-1, aA-crystallin and fibroblast growth factor 19 (FGF19), are isoform-specific and mainly response to the FXRa2 and FXRa4 isoforms [1-3].

Breast cancer is the most frequently diagnosed cancer and the leading cause of cancer death among females, accounting for $23 \%$ of the total cancer cases and $14 \%$ of the cancer deaths [4]. Mammary tumors present highly complexity and heterogeneity, while global understanding of the underlined molecular mechanisms governing their origin and progression is still lucking [5]. Molecular imaging has been considered to exert a promising role in complementing and overcoming some of the limitations of traditional biomarkers by providing the ability to perform noninvasive, repeatable whole-body assessments [6]. Estrogen receptor (ER), progesterone receptor (PR) and human epidermal growth factor receptor 2 (HER2) define prognosis and identify tumors for targeted therapy, and remain the sole established single-molecule biomarkers defining the minimum breast cancer pathology data set [7]. 
ER-targeted endocrine therapies are effective for the treatment of patients with ER-positive breast tumors and tamoxifen is currently the most widely used endocrine anti-estrogen treatment [8].

In the last decade, FXR has been implicated in the pathogenesis of cholestatic, non-alcoholic fatty liver and inflammatory bowel disease [9-11]. FXR has also been involved in the development of atherosclerosis, intestinal bacterial growth and liver regeneration [12-14]. Notably, recent accumulative evidence has further suggested that FXR may exert a potential protective role against tumorigenesis by promoting apoptosis and inhibiting cell proliferation, as recently critically reviewed by our group $[15,16]$. However, apart from the gradually increasing research conducted on cultured cell lines and animal models, there is no comprehensive clinical data so far concerning the involvement of FXR in human malignant transformation [15]. In fact, certain small pilot cohort studies have currently been conducted on esophageal, breast, hepatocellular, pancreatic and colon carcinoma; however, most of them did not concern potential associations of FXR expression with clinicopathological parameters and patients' prognosis [17-25]. In addition, there are also clinical data suggesting that FXR was highly expressed in breast cancer, being associated with tumor cells' proliferative capacity and ER status $[18,19,26]$; however, its clinical and prognostic value has not been evaluated yet.

In view of the above considerations, the present study is aimed to evaluate the immunohistochemical expression of FXR in invasive breast carcinoma tissue samples in association with multiple clinicopathological characteristics, ER, PR and HER2 expression, as well as with overall and disease-free patients' survival.

\section{Patients and methods}

Patients. One hundred fifteen patients aged from 32 to 87 years (mean 57.6 years) who underwent surgical resection due to invasive breast carcinoma were included in this study. None of them had received radiation or chemotherapy preoperatively. The study was approved by the institutional ethical committee of the Medical School of the University of Athens. Informed consent was signed by all patients under study in order to use for research purposes their biological samples and clinical data [27].

Routine histological examination was performed with haematoxylin and eosin staining. All cases were classified in accordance with World Health Organization criteria [28] and were recorded as invasive ductal or lobular carcinoma. Nuclear grading was based on nuclear pleomorphism. Staging at the time of diagnosis was based on the TNM system [29]. The combined histological grade (1,2 or 3) of infiltrating ductal and lobular carcinomas was obtained according to a modified Scarff-BloomRichardson histological system with guidelines as suggested by Nottingham City Hospital pathologists [30]. The clinicopathological characteristics of the series are shown in Table 1.
Table 1. Associations between FXR expression and clinicopathological parameters in 115 patients with invasive breast carcinoma

\begin{tabular}{|c|c|c|c|}
\hline \multirow{2}{*}{$\begin{array}{l}\text { Clinicopathological } \\
\text { parameters }\end{array}$} & \multicolumn{3}{|c|}{ FXR expression } \\
\hline & Low (\%) & High (\%) & p-value \\
\hline $\mathrm{N}=115$ & $64(55.7)$ & $51(44.3)$ & \\
\hline Age (mean $\pm S D ; y s)$ & & & 0.9843 \\
\hline$\leq 57.6 \pm 12.6 \mathrm{yrs}$ & $30(26.1)$ & $24(20.9)$ & \\
\hline$>57.6 \pm 12.6 \mathrm{yrs}$ & $34(29.6)$ & $27(23.5)$ & \\
\hline Menopausal status & & & 0.8453 \\
\hline Premenopausal & $19(16.5)$ & $16(13.9)$ & \\
\hline Postmenopausal & $45(39.1)$ & $35(30.4)$ & \\
\hline Histopathological type & & & 0.9150 \\
\hline Ductal & 47 (40.9) & $37(32.2)$ & \\
\hline Lobular & $17(14.8)$ & $14(12.2)$ & \\
\hline Histological Grade & & & 0.3141 \\
\hline 1 & $5(4.4)$ & $5(4.4)$ & \\
\hline 2 & $30(26.1)$ & $30(26.1)$ & \\
\hline 3 & $29(22.2)$ & $16(13.9)$ & \\
\hline Nuclear Grade & & & 0.4350 \\
\hline 1 & $26(22.6)$ & $26(22.6)$ & \\
\hline 2 & $18(15.7)$ & $14(12.2)$ & \\
\hline 3 & $20(17.4)$ & $11(9.6)$ & \\
\hline Molecular subtype & & & 0.8580 \\
\hline Luminal-A & $28(24.3)$ & $25(21.7)$ & \\
\hline Luminal-B & $9(7.8)$ & $7(6.1)$ & \\
\hline HER2 & $8(7.0)$ & $4(3.5)$ & \\
\hline Triple negative & $19(16.5)$ & $15(13.0)$ & \\
\hline Tumor size & & & 0.0318 \\
\hline pT1 & $15(13.0)$ & $16(13.9)$ & \\
\hline pT2 & $39(33.9)$ & $34(29.6)$ & \\
\hline pT3 & $10(8.7)$ & $1(0.9)$ & \\
\hline Lymph nodes & & & 0.7474 \\
\hline Non infiltrated & $27(23.5)$ & $20(17.4)$ & \\
\hline Infiltrated & $37(32.2)$ & $31(27.0)$ & \\
\hline Histopathological stage & & & 0.5657 \\
\hline I & $11(9.6)$ & $12(10.4)$ & \\
\hline II & $42(36.5)$ & $33(28.7)$ & \\
\hline III & $11(9.6)$ & $6(5.2)$ & \\
\hline ER expression & & & 0.9505 \\
\hline Negative & $33(28.7)$ & $26(22.6)$ & \\
\hline Positive & $31(27.0)$ & $25(21.7)$ & \\
\hline PR expression & & & 0.4161 \\
\hline Negative & $35(30.4)$ & $24(20.9)$ & \\
\hline Positive & $29(25.2)$ & $27(23.5)$ & \\
\hline HER-2 expression & & & 0.4170 \\
\hline Negative & $56(48.7)$ & $47(40.9)$ & \\
\hline Positive & $8(7.0)$ & $4(3.5)$ & \\
\hline Ki-67 protein statement & & & 0.0375 \\
\hline Below median value & $37(32.2)$ & $20(17.4)$ & \\
\hline Over median value & $27(23.5)$ & $31(27)$ & \\
\hline
\end{tabular}


The patients were followed up for a time interval of 8 up to 210 months with a mean survival time of $84.6 \pm 45.0$ months. Overall survival was defined as the time interval between the date of surgery and the date of death due to breast carcinoma or the last follow-up. Disease-free survival was defined as the time interval between the date of surgery and the date of detection of recurrence or the date of last follow-up without recurrence for breast carcinoma. At the time of the last follow-up, 21 (18.3\%) patients had died from disease, $11(9.6 \%)$ were alive with disease and 79 (68.7\%) were alive and disease-free. All patients received conventional postoperative treatment depending on the disease extent, including adjuvant chemotherapy, radiation therapy and anti-estrogen therapy, when indicated, according to the consensus recommendations at the time [27].

Immunohistochemistry. Immunohistochemistry was performed on $4 \mu \mathrm{m}$ formalin-fixed paraffin embedded breast tissue sections using commercially available rabbit polyclonal anti-FXR (H-130, sc13063, Santa Cruz Biochemicals, Santa Cruz, CA, USA). The immunohistochemistry was performed in automated immunohistochemical stainer (Bond, Leica Biosystems) with Bond Polymer Refine Detection System. The protocol in immunostainer was: Antigen retrieval with ER1 solution (citrate buffer $\mathrm{pH}$ 6.0) for 20 minutes, incubation with marker (anti-FXR dilution 1:75) for 30 minutes, incubation with postprimary reagent 15 minutes and with polymer reagent 15 minutes. Appropriate negative controls were performed by omitting the primary antibody and/or substituting it with an irrelevant anti-serum. As positive control, pancreatic adenocarcinoma tissue sections with known increased FXR expression was used [22]. The tumor cells' proliferative capacity was assessed immunohistochemically, using a mouse anti-human Ki-67 antigen; IgG1k antibody (clone MIB-1, Dakopatts, Glostrup, Denmark) as previously described [22]. The expression of ER, PR and HER2 was assessed immunohistochemically, as previously described [27].

Evaluation of immunohistochemistry. Immunohistochemical evaluation was performed by counting at least 1000 tumor cells in each case by two independent observers (S.T. and P.A.) blinded to the clinical data, with complete observer agreement. Specimens were considered "positive" for FXR when more than $5 \%$ of tumor cells within the section were positively stained. FXR immunoreactivity was scored according to the percentage of positive tumor cells as 0 : negative staining- $0-4 \%$ of cells positive; $1: 5-24 \%$ of cells positive; 2: $25-49 \%$ of cells positive; $3: 50-100 \%$ of cells positive, and its intensity as 0 : negative staining, 1 : mild staining; 2 : intermediate staining; 3 : intense staining. Finally, the expression of FXR was classified as low; if the total score was 0 or 2 and high; if the total score was $\geq 3$. In this way, we ensure that each group has a sufficient and more homogeneous number of cases in order to be comparable with the other groups [22, 31, 32].

Staining for ER and PR was evaluated according to CAP/ ASCO recommendations, i.e. ER and PR assays are considered positive if there are at least $1 \%$ positive tumor nuclei in the sample in the presence of the expected reactivity of internal and external controls [33]. The fraction of HER2 positive stained cells was scored from 0 to 3 according to CAP/ASCO guidelines [34]. Ki-67 immunoreactivity was classified according to the percentage of positively stained tumor cells exceeded the median percentage value into two categories (below and over mean value), as previously reported [22, 31, 32].

Statistical analysis. Chi-square test was used to assess the associations of FXR protein expression with clinicopathological variables and ER, PR, HER2 and Ki-67 protein expression. Survival curves were constructed using the Kaplan-Meier method and the differences between the curves were compared by the log rank test. A Cox proportional-hazard regression model was developed to evaluate the association between the potential prognostic marker and overall survival, at multivariate level. A p-value less than 0.05 was considered the limit of statistical significance. SPSS for Windows Software was used for all analyses (SPSS Inc., 2003, Chicago, USA).

\section{Results}

FXR positivity (IHC score $>0$ ) was noted in $91(79.1 \%)$ out of 115 invasive breast carcinoma cases. Fifty-one (44.3\%) out of the 115 examined cases presented high FXR expression (IHC score $\geq 3$ ). The subcellular pattern of FXR distribution was cytoplasmic in 35 (38.5\%), nuclear in 9 (9.9\%) and both cytoplasmic and nuclear in 47 (51.7\%) out of the 91 FXRpositive cases. Forty-seven (52.8\%) out of 91 FXR-positive invasive breast cancer cases presented mild staining intensity, while $35(38.5 \%)$ and 8 (8.8\%) out of 91 FXR-positive invasive breast carcinoma cases presented moderate or intense staining intensity, respectively. Low FXR expression levels were noted in normal breast cells, adjacent to tumor, or in carcinoma in situ cases. Normal ductal cells were either FXR-negative or presented mild to moderate FXR nuclear and/or mild cytoplasmic pattern of immunostaining (Figure 1A). Similar expression pattern was also noted in the case of breast in situ carcinoma (Figure 1B), although increased percentage of positive cells was found when compared with normal breast. Representative FXR immunostainings in breast invasive carcinoma cases presenting mild, moderate and intense staining intensity are depicted in Figure 2A, 2B and 2C, respectively. Fifty-six (58.7\%) out of 115 invasive breast carcinoma cases were ER positive. PR positivity was noted in 56 (58.7\%) out of 115 cases, while $12(10.4 \%)$ cases were HER2 positive. Fifty-three (46.1\%) out of 115 breast carcinoma cases were classified as luminal-A, 16 $(13.9 \%)$ cases as luminal-B, $34(29.6 \%)$ as triple negative and $12(10.4 \%)$ as HER2-phenotype.

High FXR expression was significantly more frequently observed in invasive breast carcinoma patients presenting smaller tumor size (Table 1, $\mathrm{p}=0.0318$ ). High FXR expression was also significantly associated with increased tumor cells' proliferative rate (Table 1, p=0.0375). An increased incidence of high FXR expression was noted in invasive breast carcinoma patients with low histological and nuclear grade, at a no significant level though (Table $1, \mathrm{p}=0.3141$ and $\mathrm{p}=0.4350$, respectively). 

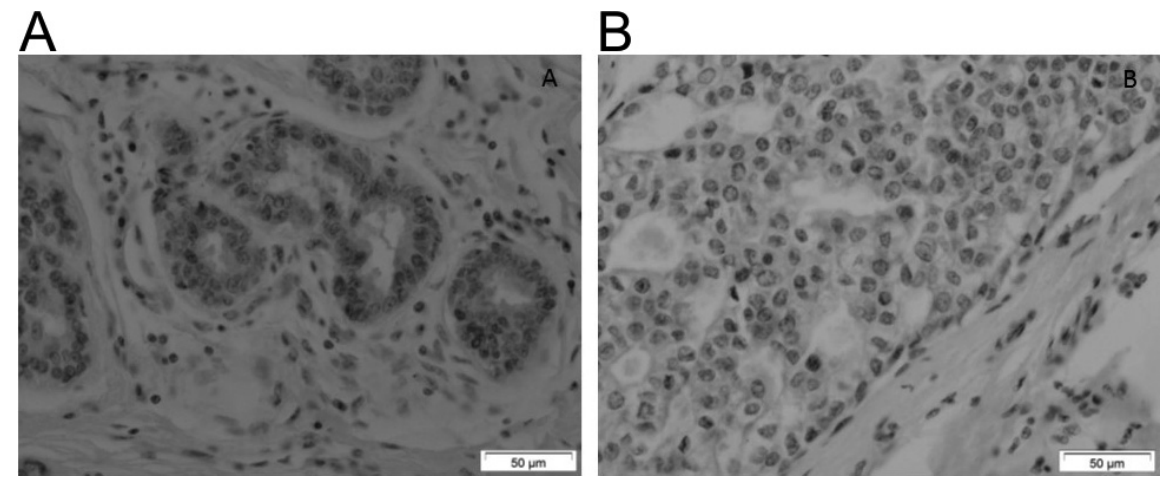

Figure 1. Representative FXR immunostainings in normal breast ductules (A) and in breast carcinoma in situ (B) (original magnification X200, scale bars are present on figures).

High FXR expression was also more frequently observed in breast carcinoma patients presenting earlier disease stage, at a no significant level though ( $\mathrm{p}=0.5657)$. None associations or trends of correlation between FXR expression and the other clinicopathological parameters examined were noted (Table 1). FXR expression was not different between the molecular breast carcinoma subtypes (Table 1).

Kaplan-Meier survival curves indicated that invasive breast carcinoma patients presenting high FXR expression showed significantly longer overall and disease-free survival times compared to those with low FXR expression (Figure 3A and $3 \mathrm{~B}, \log$-rank test, $\mathrm{p}=0.0052$ and $\mathrm{p}=0.0058$, respectively). In multivariate analysis, nuclear grade, histopathological stage, Ki-67 protein statement and FXR expression were identified as independent prognostic factors of overall patients' survival (Table 2, Cox-regression analysis, $\mathrm{p}=0.0498, \mathrm{p}=0.0053$, $\mathrm{p}=0.0093$ and $\mathrm{p}=0.0023$, respectively). Histopathological stage, Ki-67 protein statement and FXR expression were also identified as independent prognostic factors of disease-free patients' survival (Table 2, Cox-regression analysis, $\mathrm{p}=0.0018, \mathrm{p}=0.0437$ and $\mathrm{p}=0.0029$, respectively).

\section{Discussion}

Undergoing research is currently focused on the role of FXR in crucial biochemical and cellular processes implicated in several pathological disease states, such as cholestatic, non-alcoholic fatty liver and inflammatory bowel disease, atherosclerosis, intestinal bacterial growth and liver regeneration, as recently reviewed by our group $[15,16]$. A gradually growing body of in vitro and animal studies has further extended the role of FXR in oncogenic transformation $[15,16]$. However, the assessment of the clinical significance of FXR expression in human malignancies remains scarce, being restricted to a small number of pilot cohort studies that mostly did not concern associations with clinicopathological parameters and patients' prognosis [17-25]. Moreover, there is not any clinical data up to now concerning the prognostic significance of FXR in invasive breast carcinoma.

In this aspect, the present study assessed the FXR expression levels in tumoral samples of invasive breast carcinoma patients, investigating for their association with crucial clinicopathological characteristics and patients' survival.

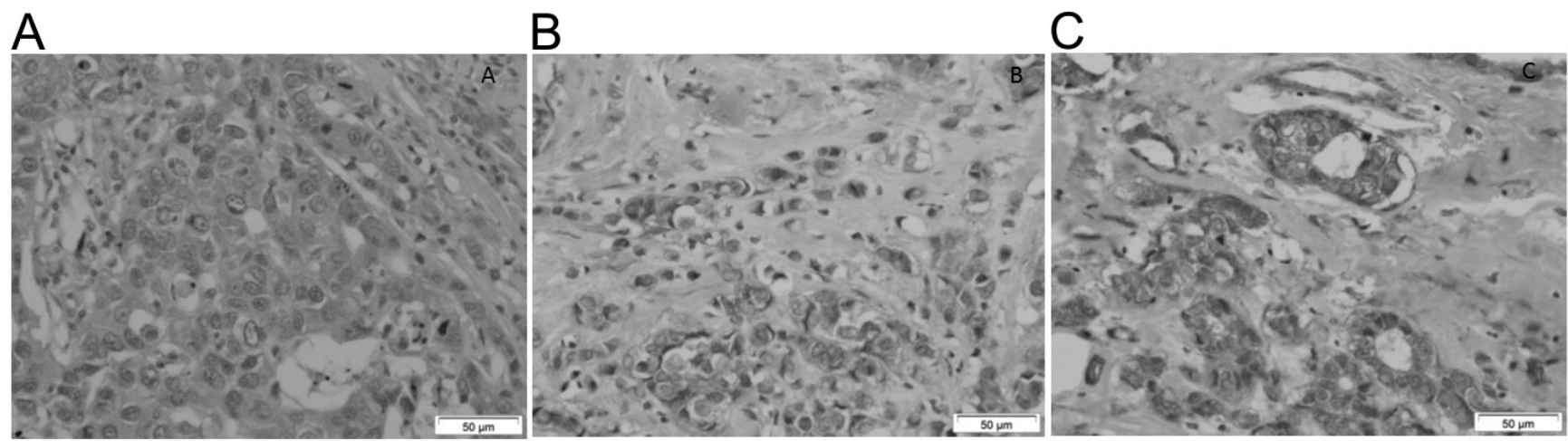

Figure 2. Representative FXR immunostainings in breast carcinomas presenting mild (A), moderate (B) and intense (C) staining intensity (original magnification X200, scale bars are present on figures). 


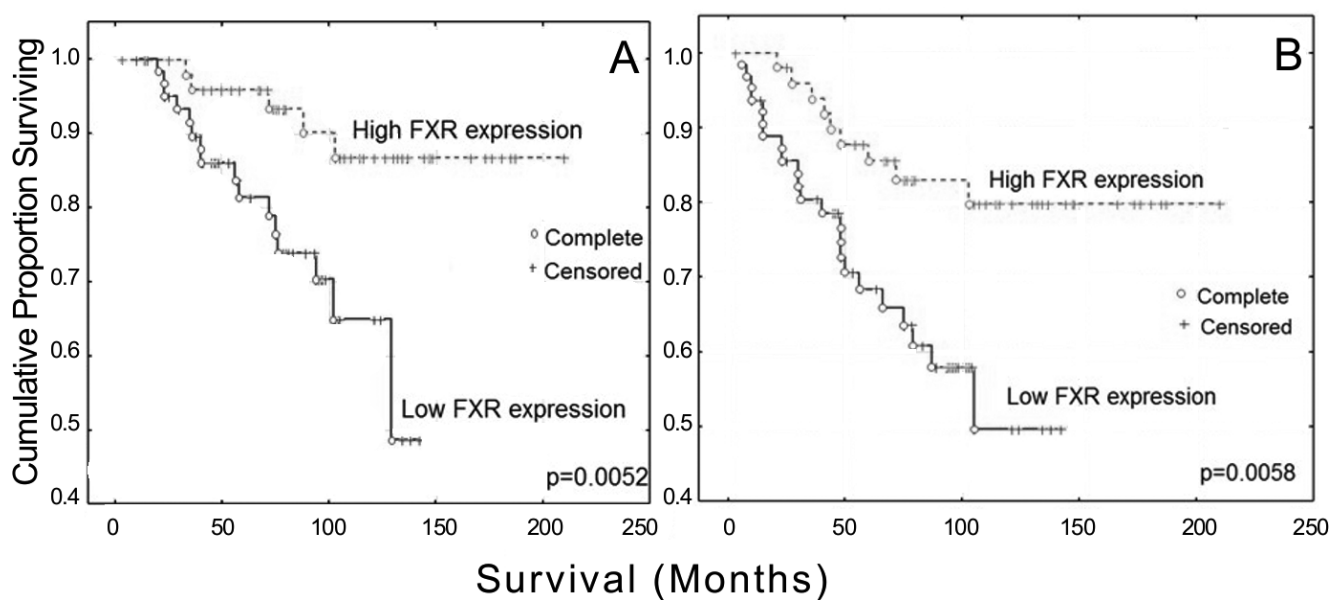

Figure 3. Kaplan-Meier survival analysis stratified according to FXR expression in 115 breast carcinoma patients: (A) Overall patients' survival and (B) Disease-free patients' survival.

According to our results, approximately half of the examined invasive breast carcinoma cases presented high FXR expression levels and all the examined cases presented negative or mild nuclear FXR immunostaining in non-malignant breast tissue. Moreover, it should be noted that FXR subcellular distribution was found predominately cytoplasmic in the vast majority (89.6\%) of the examined breast carcinoma cases. The above finding may suggest that either FXR may not be translocated to the nucleus remaining in the cytoplasm or the excess amount produced was retained in the cytoplasm in malignant disease state.

The present study also showed that high FXR expression was associated with smaller tumor size. At the same time, a positive association between FXR and tumor cells' proliferative rate was recorded. Moreover, we found that high FXR expression is associated with longer overall and disease-free patients' survival at both univariate and multivariate level. Thus, it could be speculated that FXR is a strong and independent prognosticator of favorable overall and disease-free survival in invasive breast carcinoma. Such data also reinforces the therapeutic utility of its targeting in breast cancer chemoprevention, since several in vitro and animal studies have documented that FXR may be considered as a potential molecular target in breast neoplasia [15].
As far as concern the existing data so far on breast neoplasia, an immunohistochemical study was initially performed on 10 breast carcinoma tissue samples and identified FXR expression in both the ductal epithelial cells of normal breast and infiltrating ductal adenocarcinoma cells [18]. Moreover, enhanced FXR expression was shown in breast carcinoma cell lines MCF-7 (ER-positive) and MDA-MB-231 (ER-negative) [18]. A more recent study conducted on 204 breast carcinoma patients showed that FXR expression was significantly correlated with the proliferation marker Ki-67 and the nodal status [19]. Moreover, this study documented that FXR expression was positively correlated with ER and PR expression and luminal-phenotype [19]. In contrast, we did not find any association between FXR and ER or PR expression. This controversy may be ascribed to the fact that the above study [19] considered nuclear staining to define FXR expression, whereas in the present study both cytoplasmic and nuclear staining were taken into account to semi-quantify FXR expression. Moreover, the above study [19] reported exclusively nuclear FXR staining, whereas in our study the vast majority of the examined breast carcinoma cases presented cytoplasmic or both cytoplasmic and nuclear staining. This discrepancy may also be ascribed to the different primary antibody used to detect FXR immunoreactivity. In another study by the same

Table 2. Multivariate analysis for nuclear grade, histopathological stage, Ki-67 statement and FXR expression for overall and disease-free patients' survival

\begin{tabular}{|c|c|c|c|c|}
\hline \multirow{2}{*}{$\begin{array}{l}\text { Clinicopathological } \\
\text { Variables }\end{array}$} & \multicolumn{2}{|c|}{ Overall survival } & \multicolumn{2}{|c|}{ Disease-free survival } \\
\hline & HR (95\% CI) & p-value & HR (95\% CI) & p-value \\
\hline Nuclear Grade (I / II+III) & $2.766(1.095-3.656)$ & 0.0498 & $2.015(0.873-3.976)$ & 0.1636 \\
\hline Histopathological stage (I+II / III) & $4.048(2.875-6.755)$ & 0.0053 & $3.351(2.018-6.129)$ & 0.0018 \\
\hline Ki-67 statement (Below/over median value) & $3.695(2.229-6.452)$ & 0.0093 & $2.124(0.984-3.685)$ & 0.0437 \\
\hline FXR expression (Low / High) & $0.183(0.022-0.589)$ & 0.0023 & $0.289(1.257-2.598)$ & 0.0029 \\
\hline
\end{tabular}


group, immunohistochemical analysis on 65 breast carcinoma samples established significant correlations between FXR expression and ER, Ki-67 and topoisomerase-II alpha expression [26]. Interestingly, activation of FXR by the primary bile acid chenodeoxycholic acid or the synthetic agonist GW4064, inhibited growth of tamoxifen-resistant breast cancer cells, in vitro, through downregulation of HER2 expression, which emphasized the importance of targeting FXR in breast cancer [35].

Concerning the existing clinical evidence so far in other human malignancies, FXR expression was inversely correlated with neoplastic transformation/progression and inflammation severity in ulcerative colitis [24]. Moreover, primary sclerosing cholangitis - ulcerative colitis patients presented diminished FXR expression in the proximal colon compared to ulcerative colitis patients [24]. In human hepatocellular carcinoma, FXR expression was down-regulated, being positively correlated with multiple malignant clinicopathological characteristics [21]. FXR overexpression was also associated with poor histopathological grade, larger tumor size and presence of lymph node metastasis in 59 esophageal adenocarcinoma patients [23]. In another study, FXR was detected in non-dysplastic tissue, but its expression was lost during progression to dysplasia and adenocarcinoma in Barrett's esophagus patients [20]. FXR mRNA levels were reduced in adenomas compared to normal colorectal mucosa, while an even more pronounced decrease in colon carcinomas was recorded [17]. In another study, FXR expression was reduced in colon carcinoma compared to peritumoral nonneoplastic mucosa [25]. Loss of FXR expression was correlated with high tumor grade in the right colon. Moreover, FXR expression in tumor and normal colon tissue showed an inverse correlation with histopathological stage, while FXR expression in tumor was inversely correlated with clinical outcome [25]. At last, in a recent cohort study conducted by our group on 55 pancreatic adenocarcinoma patients, enhanced FXR expression was associated with earlier histopathological stage [22]. Moreover, FXR expression was identified as a strong and independent prognosticator of favorable overall patients' survival [22].

Conclusions. The present study supported clinical evidence that FXR expression is a strong and independent prognosticator of favorable overall and disease-free survival in invasive breast carcinoma. FXR seems to be implicated at the earlier stage of breast malignant disease progression. The present study further suggested that FXR translocation from nucleus to cytoplasm may be a potential event during malignant breast transformation process. In this aspect, additional research conducted on larger cohorts and on each molecular subtype separately could evaluate whether FXR may be considered of diagnostic and prognostic utility in breast neoplasia, exploring also its usefulness as potential therapeutic target in breast neoplasia.

\section{References}

[1] PELLICCIARI R, COSTANTINO G, FIORUCCI S. Farnesoid $\mathrm{X}$ receptor: from structure to potential clinical applications.
J Med Chem 2005; 48: 5383-5403. https://doi.org/10.1021/ im0582221

[2] WANG YD, CHEN WD, MOORE DD, HUANG W. FXR: a metabolic regulator and cell protector. Cell Res 2008; 18: 1087-1095. https://doi.org/10.1038/cr.2008.289

[3] ZHANG Y, KAST-WOELBERN HR, EDWARDS PA. Natural structural variants of the nuclear receptor farnesoid $\mathrm{X}$ receptor affect transcriptional activation. J Biol Chem 2003; 278: 104-110. https://doi.org/10.1074/jbc.M209505200

[4] JEMAL A, BRAY F, CENTER MM, FERLAY J, WARD E et al. Global cancer statistics. CA Cancer J Clin 2011; 61: 69-90. https://doi.org/10.3322/caac.20107

[5] SKIBINSKI A, KUPERWASSER C. The origin of breast tumor heterogeneity. Oncogene 2015; 34: 5309-5316. https://doi. org/10.1038/onc.2014.475

[6] ULANER GA, RIEDL CC, DICKLER MN, JHAVERI K, PANDIT-TASKAR N et al. Molecular Imaging of Biomarkers in Breast Cancer. J Nucl Med 2016; 57: 53S-59S. https://doi. org/10.2967/jnumed.115.157909

[7] KOS Z, DABBS DJ. Biomarker assessment and molecular testing for prognostication in breast cancer. Histopathology 2016; 68: 70-85. https://doi.org/10.1111/his.12795

[8] WANG L, GALLO KA, CONRAD SE. Targeting mixed lineage kinases in ER-positive breast cancer cells leads to G2/M cell cycle arrest and apoptosis. Oncotarget 2013; 4: 1158-1171. https://doi.org/10.18632/oncotarget.1093

[9] JONKER JW, LIDDLE C, DOWNES M. FXR and PXR: potential therapeutic targets in cholestasis. J Steroid Biochem Mol Biol 2012; 130: 147-158. https://doi.org/10.1016/j. jsbmb.2011.06.012

[10] ADORINI L, PRUZANSKI M, SHAPIRO D. Farnesoid X receptor targeting to treat nonalcoholic steatohepatitis. Drug Discov Today 2012; 17: 988-997. https://doi.org/10.1016/j. drudis.2012.05.012

[11] STOJANCEVIC M, STANKOV K, MIKOV M. The impact of farnesoid $\mathrm{X}$ receptor activation on intestinal permeability in inflammatory bowel disease. Can J Gastroenterol 2012; 26: 631-637. https://doi.org/10.1155/2012/538452

[12] MENCARELLI A, FIORUCCI S. FXR an emerging therapeutic target for the treatment of atherosclerosis. J Cell Mol Med 2010; 14: 79-92. https://doi.org/10.1111/j.15824934.2009.00997.x

[13] GADALETA RM, VAN MIL SW, OLDENBURG B, SIERSEMA PD, KLOMP LW et al. Bile acids and their nuclear receptor FXR: Relevance for hepatobiliary and gastrointestinal disease. Biochim Biophys Acta 2010; 1801: 683-692. https://doi.org/10.1016/j.bbalip.2010.04.006

[14] HUANG W, MA K, ZHANG J, QATANANI M, CUVILLIER J et al. Nuclear receptor-dependent bile acid signaling is required for normal liver regeneration. Science 2006; 312: 233-236. https://doi.org/10.1126/science.1121435

[15] KOUTSOUNAS I, GIAGINIS C, THEOCHARIS S. Farnesoid $\mathrm{X}$ Receptor (FXR) from normal to malignant state. Histol Histopathol 2012; 27: 835-853.

[16] KOUTSOUNAS I, THEOCHARIS S, DELLADETSIMA I, PATSOURIS E, GIAGINIS C. Farnesoid x receptor in human metabolism and disease: the interplay between gene polymor- 
phisms, clinical phenotypes and disease susceptibility. Expert Opin Drug Metab Toxicol 2015; 11: 523-532. https://doi.org/ 10.1517/17425255.2014.999664

[17] DE GOTTARDi A, TOURI F, MAURER CA, PEREZ A, MAURHOFER $O$ et al. The bile acid nuclear receptor FXR and the bile acid binding protein IBABP are differently expressed in colon cancer. Dig Dis Sci 2004; 49: 982-989. https://doi. org/10.1023/B:DDAS.0000034558.78747.98

[18] SWALES KE, KORBONITS M, CARPENTER R, WALSH DT, WARNER TD et al. The farnesoid X receptor is expressed in breast cancer and regulates apoptosis and aromatase expression. Cancer Res 2006; 66: 10120-10126. https://doi. org/10.1158/0008-5472.CAN-06-2399

[19] JOURNE F, DURBECQ V, CHABOTEAUX C, ROUAS G, LAURENT G et al. Association between farnesoid X receptor expression and cell proliferation in estrogen receptor-positive luminal-like breast cancer from postmenopausal patients. Breast Cancer Res Treat 2009; 115: 523-535. https://doi. org/10.1007/s10549-008-0094-2

[20] VAN DE WINKEL A, VAN ZOEST KP, VAN DEKKEN H, MOONS LM, KUIPERS EJ et al. Differential expression of the nuclear receptors farnesoid X receptor (FXR) and pregnane $\mathrm{X}$ receptor (PXR) for grading dysplasia in patients with Barrett's oesophagus. Histopathology 2011; 58: 246-253. https://doi. org/10.1111/j.1365-2559.2011.03743.x

[21] SU H, MA C, LIU J, LI N, GAO M et al. Downregulation of nuclear receptor FXR is associated with multiple malignant clinicopathological characteristics in human hepatocellular carcinoma. Am J Physiol Gastrointest Liver Physiol 2012; 303: G1245-1253. https://doi.org/10.1152/ajpgi.00439.2011

[22] GIAGINIS C, KOUTSOUNAS I, ALEXANDROU P, ZIZISERBETZOGLOU A, PATSOURIS E et al. Elevated Farnesoid X Receptor (FXR) and Retinoid X Receptors (RXRs) expression is associated with less tumor aggressiveness and favourable prognosis in patients with pancreatic adenocarcinoma. Neoplasma 2015; 62:332-341. https://doi.org/10.4149/ neo $2015 \quad 040$

[23] GUAN B, LI H, YANG Z, HOQUE A, XU X. Inhibition of farnesoid $X$ receptor controls esophageal cancer cell growth in vitro and in nude mouse xenografts. Cancer 2013; 119: 1321-1329. https://doi.org/10.1002/cncr.27910

[24] TORRES J, BAO X, IUGA AC, CHEN A, HARPAZ N et al. Farnesoid X receptor expression is decreased in colonic mucosa of patients with primary sclerosing cholangitis and colitis-associated neoplasia. Inflamm Bowel Dis 2013; 19: 275-282. https://doi.org/10.1097/MIB.0b013e318286ff2e

[25] LAX S, SCHAUER G, PREIN K, KAPITAN M, SILBERT D et al. Expression of the nuclear bile acid receptor/farnesoid $\mathrm{X}$ receptor is reduced in human colon carcinoma compared to nonneoplastic mucosa independent from site and may be associated with adverse prognosis. Int J Cancer 2012; 130: 2232-2239. https://doi.org/10.1002/ijc.26293

[26] JOURNE F, LAURENT G, CHABOTEAUX C, NONCLERCQ D, DURBECQ V et al. Farnesol, a mevalonate pathway intermediate, stimulates MCF-7 breast cancer cell growth through farnesoid-X-receptor-mediated estrogen receptor activation. Breast Cancer Res Treat 2008; 107: 49-61. https:// doi.org/10.1007/s10549-007-9535-6

[27] MYLONA E, VAMVAKARIS I, GIANNOPOULOU I, THEOHARI I, PAPADIMITRIOU C et al. An immunohistochemical evaluation of the proteins Wnt 1 and glycogen synthase kinase (GSK)-3 $\beta$ in invasive breast carcinomas. Histopathology 2013; 62: 899-907. https://doi.org/10.1111/his.12095

[28] ELLIS IO, SCHNITT SJ, SASTRE-GARAU X, BUSSOLATI G, TAVASSOLI FA et al. Invasive breast carcinoma, p 13-41. In: Tavassoli FA, Devilee P. (Eds). World Health Organization Classification of Tumours. Pathology and Genetics of Tumours of the Breast and Female Genital Organs. IARC Press, Lyon 2003, pp. 432. ISBN 9283224124

[29] ELLIS IO, SCHNITT SJ, SASTRE-GARAU X, BUSSOLATI G, TAVASSOLI FA et al. Invasive breast carcinoma, p 13-41. In: Tavassoli FA, Devilee P. (Eds). World Health Organization Classification of Tumours. Pathology and Genetics of Tumours of the Breast and Female Genital Organs. IARC Press, Lyon 2003, pp. 432. ISBN 9283224124

[30] ROBINS P, PINDER S, DE KLERK N, DAWKINS H, HARVEY J et al. Histological grading of breast carcinomas: a study of interobserver agreement. Hum Pathol 1995; 26: 873-879. https://doi.org/10.1016/0046-8177(95)90010-1

[31] KOUTSOUNAS I, GIAGINIS C, ALEXANDROU P, ZIZISERBETZOGLOU A, PATSOURIS E et al. Pregnane X receptor expression in human pancreatic adenocarcinoma: associations with clinicopathologic parameters, tumor proliferative capacity, patients'survival, and retinoid X receptor expression. Pancreas 2015; 44: 1134-1140. https://doi. org/10.1097/MPA.0000000000000405

[32] GIAGINIS C, KOUROU E, GIAGINI A, GOUTAS N, PATSOURIS E et al. Platelet-activating factor (PAF) receptor expression is associated with histopathological stage and grade and patients' survival in gastric adenocarcinoma. Neoplasma 2014; 61: 309-317. https://doi.org/10.4149/ neo $2014 \quad 040$

[33] HAMMOND MEH, HAYES DF, DOWSETT M, ALLRED DC, HAGERTY KL et al. American Society of Clinical Oncology/College of American Pathologists guideline recommendations for immunohistochemical testing of estrogen and progesterone receptors in breast cancer. J Clin Oncol 2010; 28: 2784-2795. https://doi.org/10.1200/JCO.2009.25.6529

[34] WOLFF AC, HAMMOND ME, HICKS DG, DOWSETT M, MCSHANE LM et al. Recommendations for human epidermal growth factor receptor 2 testing in breast cancer: American Society of Clinical Oncology/College of American Pathologists clinical practice guideline update. J Clin Oncol 2013; 31: 3997-4013. https://doi.org/10.1200/ LCO.2013.50.9984

[35] GIORDANO C, CATALANO S, PANZA S, VIZZA D, BARONE I et al. Farnesoid X receptor inhibits tamoxifen-resistant MCF-7 breast cancer cell growth through downregulation of HER2 expression. Oncogene 2011; 30: 4129-4140. https://doi. org/10.1038/onc.2011.124 